
\title{
(s)
}

\section{Growth of Si-Doped Polycrystalline Diamond Films on AIN Substrates by Microwave Plasma Chemical Vapor Deposition}

\author{
V.S. Sedov ${ }^{1,2,{ }^{*}}$, A.A. Khomich ${ }^{1,3}$, V.G. Ralchenko ${ }^{1,2,{ }^{*}}$, A.K. Martyanov ${ }^{4}$, S.S. Savin ${ }^{4}$, O.N. \\ Poklonskaya $^{5}$ and N.S. Trofimov ${ }^{6}$
}

${ }^{1}$ General Physics Institute RAS, Vavilov str. 38, Moscow 119991, Russia

${ }^{2}$ National Research Nuclear University MEPhl, Kashirskoe shosse 31, Moscow 115409, Russia

${ }^{3}$ Institute of Radio Engineering and Electronics RAS, Vvedensky Sq. 1, Fryazino 141190, Russia

${ }^{4}$ Moscow State Institute of Radio Engineering, Electronics and Automation, Vernadsky Prospect 78, Moscow, 119454, Russia

${ }^{5}$ BelarusianStateUniversity, Nezavisimosti av. 4, Minsk, 220030, Republic of Belarus

${ }^{6}$ People's Friendship University of Russia, Ordzhonikidzhe str. 3, Moscow, 115419, Russia

\begin{abstract}
Microcrystalline diamond films doped with silicon have been grown on aluminum nitride substrates by a microwave plasma CVD. The doping has been performed via adding silane in various concentrations to $\mathrm{CH}_{4}-\mathrm{H}_{2}$ reaction gas mixture in course of the deposition process. The films produced at the substrate temperatures of 750 to $950^{\circ} \mathrm{C}$ have been characterized by SEM, AFM, Raman and photoluminescence (PL) spectroscopy to assess the effect of Si doping on the diamond structure. The doped films showed bright photoluminescence of silicon-vacancy (SiV) color centers at $738 \mathrm{~nm}$ wavelength as well as noticeable side band at $723 \mathrm{~nm}$. The optimum doping condition $\left(\mathrm{SiH}_{4} / \mathrm{CH}_{4} \approx 0.6 \%\right)$, that maximize the SiV PL emission, was determined for the range of silane concentrations $\mathrm{SiH}_{4} / \mathrm{CH}_{4}(0.0-0.9 \%)$ explored. A further PL enhancement can be achieved by increase in the substrate temperature. The applied in situ doping from gas phase is shown to be an easy and effective method to incorporate Si in diamond in a controllable way.
\end{abstract}


hot-filament CVD systems. The emission of SiV defects at $738 \mathrm{~nm}$ wavelength in photoluminescence spectrum was the only indicator of the successful $\mathrm{Si}$ doping in those films. Recently [14] we briefly reported on PL characterization of thin films on aluminum nitride substrates deposited by MPCVD by adding $\mathrm{SiH}_{4}$ in process gas. Here we present new results on microcrystalline diamond coatings produced in various regimes on the AIN substrates using monosilane gas for the doping.

\section{EXPERIMENTAL}

The diamond films were deposited on $10 \times 10 \times 0.5 \mathrm{~mm}^{3}$ polished AIN substrates in the microwave plasma CVD system ARDIS-100 $(2.45 \mathrm{GHz})$ [21] in $\mathrm{CH}_{4} / \mathrm{H}_{2}$ gas mixtures, adding $\mathrm{SiH}_{4}$ in variable concentration, under the following process parameters: total gas flow $500 \mathrm{sccm}$, gas pressure of 70 - 85 Torr and microwave power $2.5-3.8 \mathrm{~kW}$. Two series of the films were produced. In one experiment the silane vs methane gas flow ratio $\left(\mathrm{SiH}_{4} / \mathrm{CH}_{4}\right)$ was varied from $0 \%$ (no silane addition) to $0.9 \%$, while the microwave power ( $3.3 \mathrm{~kW})$, gas pressure $(75$ Torr $)$ and substrate temperature $800^{\circ} \mathrm{C}$ was kept constant. Another batch of the samples was prepared at the substrate temperature varied from $750^{\circ} \mathrm{C}$ to $950^{\circ} \mathrm{C}$, as measured by a two-color pyrometer (Willamson 81-35-C) by successive increase of microwave power at pressure 80 Torr, keeping constant the $\mathrm{SiH}_{4} / \mathrm{CH}_{4}$ ratio of $0.6 \%$. Prior the deposition, the substrates were seeded in a water-based slurry of detonation nanodiamond (particle average size $\sim 5$ $\mathrm{nm}, 0.2 \mathrm{wt} \%)$ by ultrasonic treatment for 15 minutes to achieve high diamond nucleation density of $10^{9}-10^{10} \mathrm{~cm}^{-2}$. The AIN substrates were intentionally chosen instead of conventional Si substrates in order to avoid any interfering Si self-doping from the substrate material via the substrate etching by atomic hydrogen of the plasma.

For correct comparison of the films obtained at different process parameters, their thickness was kept always the same $(1000 \pm 50 \mathrm{~nm})$. The film thickness and growth rate were measured in-situ with a laser interferometry technique [15] (Figure 1). The growing film was illuminated by a semiconductor laser ( $\lambda_{\text {las }}=656 \mathrm{~nm}$ wavelength) through a quartz window on top of the CVD reactor. The laser reflectivity oscillations in time $R(t)$, caused by interference in the film/substrate structure, were monitored by a portable spectrometer (Ocean Optics 4000). The distance between two neighbor maxima in the $R(t)$ signal corresponds to $\lambda_{\text {las }} / 2 n \cong 136 \mathrm{~nm}$ increment in the film thickness, where $n=2.4$ is the refraction index of diamond. No band-pass optical filter was needed to cut off the background radiation from the plasma due to high signal-to-noise ratio within narrow spectral interval around the laser wavelength.

The film surface morphology and grain size were examined with scanning electron microscopy (SEM) using Tescan MIRA3 and FEI Quanta 600 instruments. Raman spectroscopy and photoluminescence spectra were taken at room temperature (R.T.) with LABRAM HR-800 spectrometer equipped with a diode-pumped solid-state laser $(\lambda=473 \mathrm{~nm})$. The laser beam was focused in $\approx 1 \mu \mathrm{m}$ spot on the sample surface. The spectra were taken in three different locations within the central zone of each sample to assess uniformity of the samples. The variations in the intensity, peak position and width of the $1^{\text {st }}$ order Raman peals and PL SiV line were typically less than $10 \%$. The averaged parameters of the Raman and PL lines were used to analyze the trends in the spectra with the doping.

In addition, the mapping of intensity PL line at $738 \mathrm{~nm}$ wavelength was performed at R.T. with the Integra Spectra system (NT-MDT) using the spectra excitation with a $\mathrm{He}-\mathrm{Ne}$ laser at $632 \mathrm{~nm}$. The laser beam was focused in a spot of $\approx$ $0.8 \mu \mathrm{m}$ diameter and scanned across an area of up to $30 \times 30$ $\mu \mathrm{m}^{2}$ (200x200 pixels) to produce the SiV PL intensity surface distribution. The apparatus allowed measurement of the surface relief by atomic force microscopy at the same area where the PL map is taken.

\section{RESULTS AND DISCUSSION}

\subsection{SEM Characterization}

In general the undoped film and the films doped with $\mathrm{Si}$ at different silane addition in gas at fixed deposition temperature $\mathrm{T}_{\mathrm{d}}=800^{\circ} \mathrm{C}$ exhibited similar morphologies, but different grain
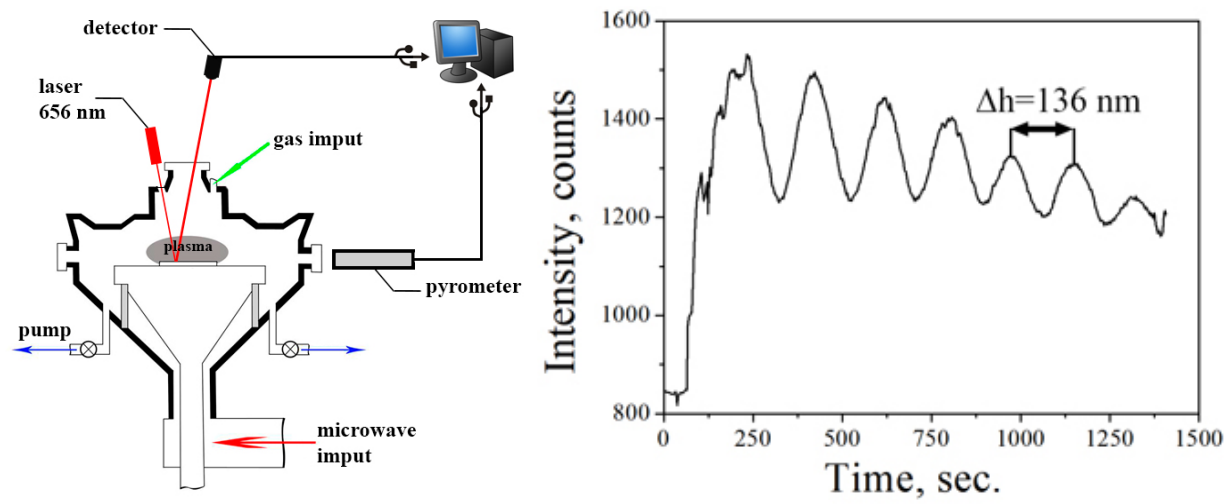

Figure 1: Schematics of in situ measurement of the film thickness by laser interferometry upon the diamond deposition (left) and typical reflection vs time oscillations (right). 


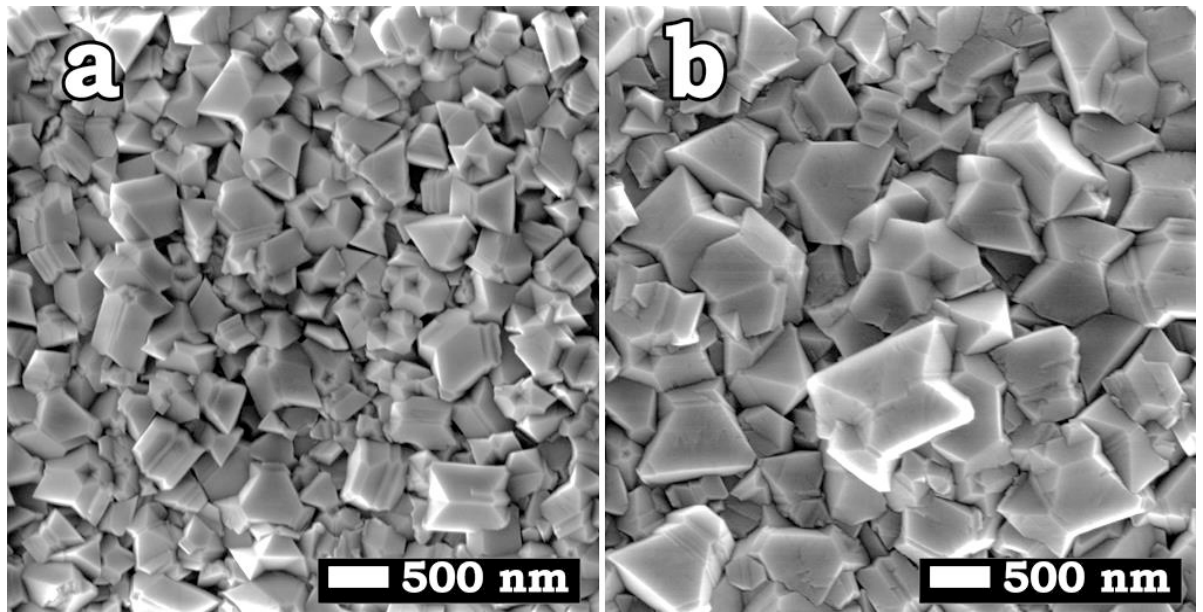

Figure 2: SEM images of undoped (a) and Si-doped at $\mathrm{SiH}_{4} / \mathrm{CH}_{4}=0.9 \%$ (b) microcrystalline diamond films deposited at $\mathrm{T}_{\mathrm{d}}=800^{\circ} \mathrm{C}$.

sizes. The SEM images of undoped and most heavily doped $\left(\mathrm{SiH}_{4} / \mathrm{CH}_{4}=0.9 \%\right)$ samples are shown in Figure 2. Both films consist of randomly oriented well faceted crystallites, with dimensions of $300-500 \mathrm{~nm}$ for the undoped film, enlarged to $500-800 \mathrm{~nm}$ for the doped ones.

The film structure was sensitive to the deposition temperature $T_{d}$. The SEM images of the growth surfaces for five films produced at different $\mathrm{T}_{\mathrm{d}}$ at fixed silane content in gas mixture $\left(\mathrm{SiH}_{4} / \mathrm{CH}_{4}=0.6 \%\right)$ is shown in Figure 3 . While the surface morphology remains unchanged at low temperatures of 750 $850^{\circ} \mathrm{C}$, a tendency for grain size decrease and more twins appearance is observed for higher $T_{d}$.

\subsection{Growth Rate}

An almost constant growth rate of $1.5 \pm 0.15 \mu \mathrm{m} / \mathrm{h}$ was determined for the films produced at $\mathrm{T}_{d}=800^{\circ} \mathrm{C}$ at different $\mathrm{SiH}_{4} / \mathrm{CH}_{4}$ ratios as shown in Figure $4 \mathrm{a}$. In contrast, the growth rate increases almost linear from 0.7 to $2.6 \mu \mathrm{m} / \mathrm{h}$ with $\mathrm{T}_{\mathrm{d}}$ elevation for the films deposited at $\mathrm{SiH}_{4} / \mathrm{CH}_{4}=0.6 \%$ (Figure 4b). Note, that at the substrate temperature $800^{\circ} \mathrm{C}$ the growth rate for the sample from of the second batch (Figure $4 \mathrm{~b}$ ) is somewhat lower $(1.25 \mu \mathrm{m} / \mathrm{h})$ compared to that for the films with variable Si doping (Figure 4a). This difference in growth rates comes from the slight difference in deposition conditions of the particular samples, the former being produced at microwave power of $3.3 \mathrm{~kW}$ and pressure of 75 Torr, while the latter at the microwave power of $3.0 \mathrm{~kW}$ and pressure of 80 Torr. Important, that the crystallinity of the films does not degrade with the growth rate as deduced from corresponding Raman spectra.

\subsection{Raman Spectra}

The Raman spectra for the films obtained at $T_{d}=800^{\circ} \mathrm{C}$ at different doping levels are shown in Figure 5. The spectra reveal the following features common for polycrystalline diamond films: (i) then arrow diamond peak at $\approx 1336 \mathrm{~cm}^{-1}$, (ii) two wide bands from trans-polyacetylene (t-PA) at $1140 \mathrm{~cm}^{-1}$ and $1480 \mathrm{~cm}^{-1}$, and (iii) D- and G-peaks at $1350 \mathrm{~cm}^{-1}$ and $1580 \mathrm{~cm}^{-1}$, respectively, from graphitic carbon [16]. The $\mathrm{sp}^{2} / \mathrm{sp}^{3}$ ratio, expressed as the ratio of the sum of $\mathrm{D}$ - and Gpeaks integrated intensities (areas under the bands) to that for $1336 \mathrm{~cm}^{-1}$ peak, is shown in Figure 6 in dependence of silane percentage added. For this analysis the diamond line at $1336 \mathrm{~cm}^{-1}$ was approximated by a Lorentzian profile, and the G- and D-peaks by two Gaussians. No increase in $\mathrm{sp}^{2}$ contribution to the entire spectrum is revealed for in the explored $\mathrm{SiH}_{4} / \mathrm{CH}_{4}$ concentration range.
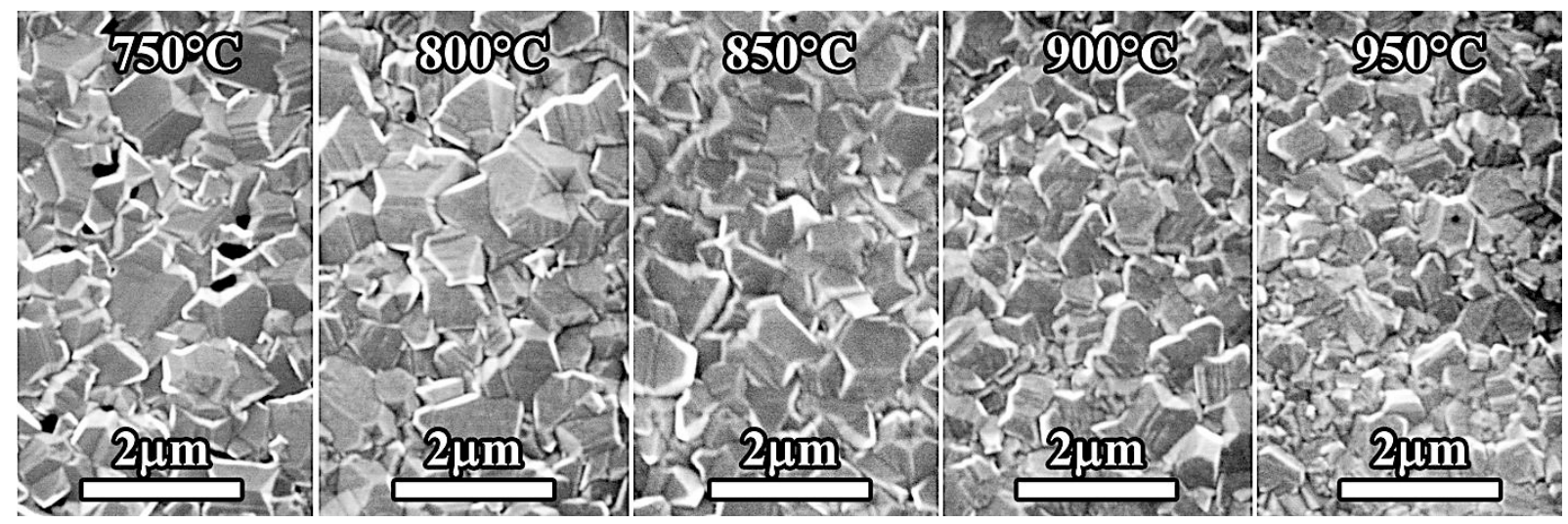

Figure 3: SEM images of Si-doped at $\mathrm{SiH}_{4} / \mathrm{CH}_{4}=0.6 \%$ diamond films grown at different substrate temperatures. 


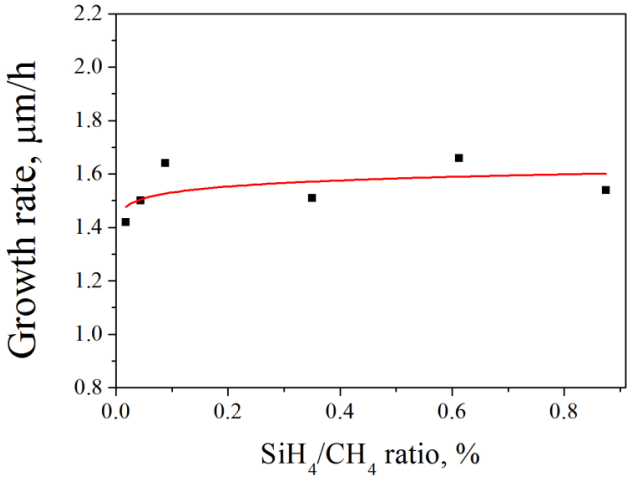

(a)

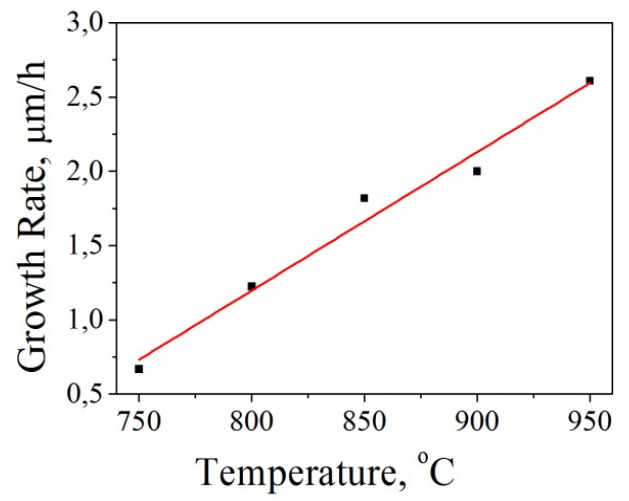

(b)

Figure 4: Dependencies of growth rate for the diamond films on $\mathrm{SiH}_{4} / \mathrm{CH}_{4}$ ratio at substrate temperature $\mathrm{T}_{\mathrm{d}}=800^{\circ} \mathrm{C}$ (a), and on substrate temperature at $\mathrm{SiH}_{4} / \mathrm{CH}_{4}=0.6 \%(\mathbf{b})$.
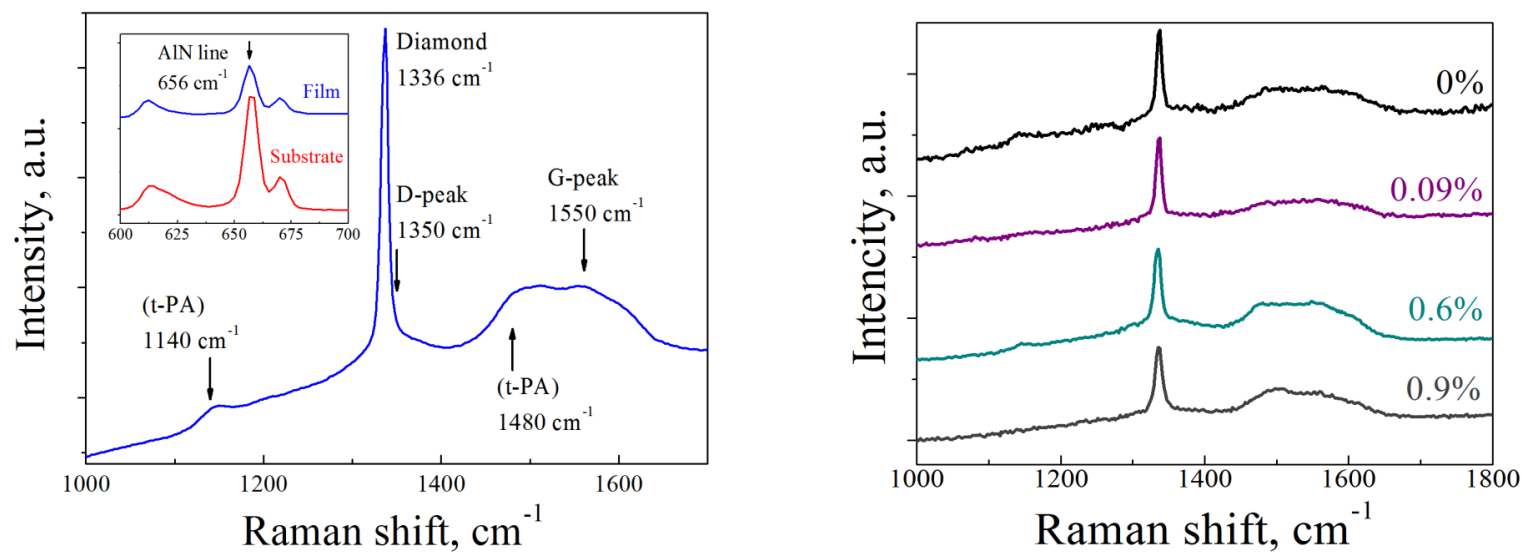

Figue 5: Raman spectra for the films grown at $\mathrm{T}_{d}=800^{\circ} \mathrm{C}$ at different $\mathrm{SiH}_{4} / \mathrm{CH}_{4}$ ratios in gas. Inset: Raman spectra in low frequency range for the bare AIN substrate and for the film produced at $\mathrm{SiH}_{4} / \mathrm{CH}_{4}=0.9 \%$, showing AIN spectrum.

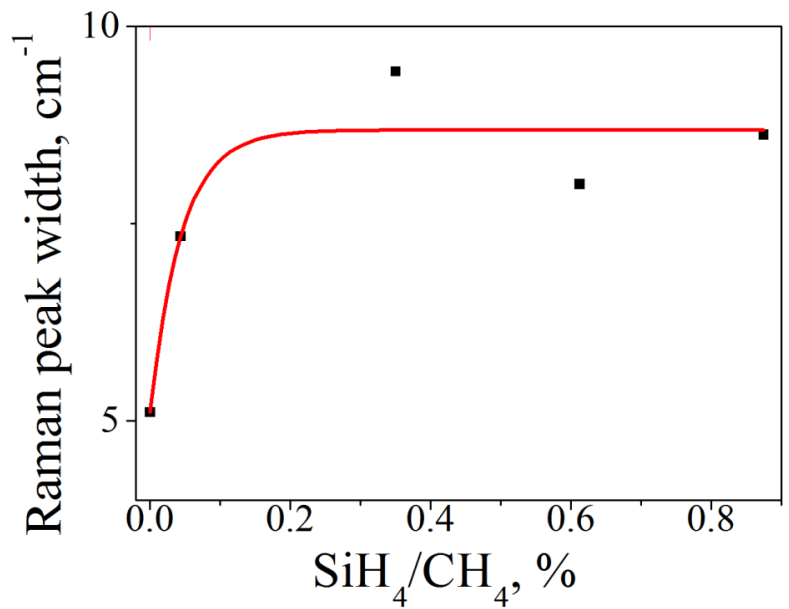

Figure 6: Diamond Raman peak width versus $\mathrm{SiH}_{4} / \mathrm{CH}_{4}$ ratio in gas at $\mathrm{T}_{\mathrm{d}}=800^{\circ} \mathrm{C}$.

At small addition of the silane a slight broadening of diamond Raman peak is observed, the full width on half magnitude (FWHM) increasing from $5.0 \mathrm{~cm}^{-1}$ for undoped film to $7.5 \mathrm{~cm}^{-1}$ for $0.04 \% \mathrm{SiH}_{4}$ sample. This might be caused by $\mathrm{Si}$ incorporation and a nonuniform stress developed as a consequence of the doping. However, no systematic further broadening of $1336 \mathrm{~cm}^{-1}$ peak and no obvious degradation of the film structure at stronger doping can be deduced from the Raman analysis.

The diamond films are found to be under compressive stress of thermal origin due to difference in thermal expansion coefficient (TEC) of AIN (mean value of $\alpha=4.5 \times 10^{-6} \mathrm{~K}^{-1}$ for the $20-500^{\circ} \mathrm{C}$ range [17]) and diamond $\left(1.0 \times 10^{-6} \mathrm{~K}^{-1}\right)$. The expected bi-axial thermal stress due to this mismatch is $\sigma=$ $E \Delta \alpha\left(T_{d}-T_{0}\right) /(1-\mu)=3.1 \mathrm{GPa}$, where $E=1040 \mathrm{GPa}$ is Young's modulus, $\mu=0.07$ is Poisson's ratio, $\Delta \alpha$ is difference in TEC for AIN and diamond, and $T_{d}$ is deposition temperature. The expected stress-induced diamond Raman peak shift $\Delta v$ is then calculated as $\Delta v\left[\mathrm{~cm}^{-1}\right]=2.05 \sigma[\mathrm{GPa}]$ [18] to give $\Delta v=6.3 \mathrm{~cm}^{-1}$, leading to the peak position of 1338.8 $\mathrm{cm}^{-1}$, while we measured the Raman peak position at $1336.1 \pm 0.2 \mathrm{~cm}^{-1}(\sigma \approx 1.8 \mathrm{GPa})$, somewhat less than the estimate based solely on thermal stress. A partial stress relaxation and/or a tensile intrinsic stress in the films could result in this difference.

Raman spectra of the films prepared at different substrate temperatures are shown in Figure 7. All of them exhibit sharp 

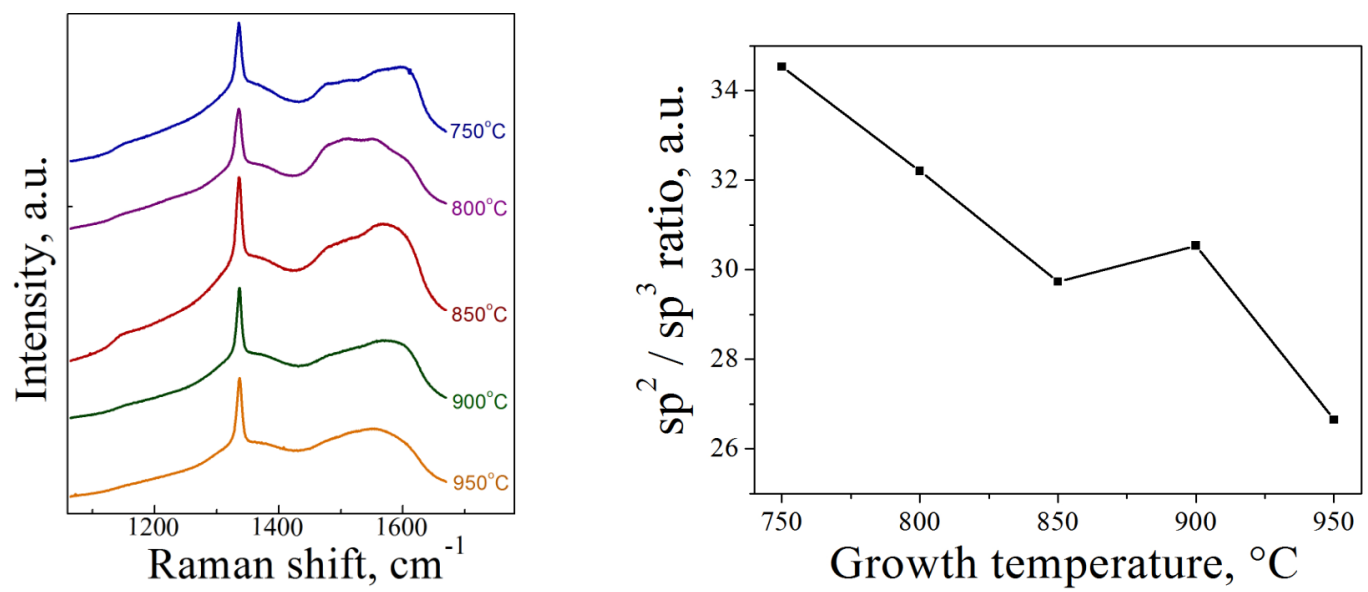

Figure 7: Raman spectra (left) and $\mathrm{sp}^{2} / \mathrm{sp}^{3}$ ratio for films prepared at different substrate temperatures at $\mathrm{SiH}_{4} / \mathrm{CH}_{4}=0.6 \%$ (right).

diamond peak near $1336 \mathrm{~cm}^{-1}$, and the features assigned to amorphous carbon and t-PA, similar to those seen in Figure 5. The $\mathrm{sp}^{2} / \mathrm{sp}^{3}$ ratio reduces by $\sim 30 \%$ with the substrate temperature increase from 750 to $950^{\circ} \mathrm{C}$ (Figure 7), indicating some improvement in diamond phase purity. The diamond Raman peak position was tend to increase from $1336.5 \mathrm{~cm}^{-1}$ $\left(750^{\circ} \mathrm{C}\right)$ to $1338.1 \mathrm{~cm}^{-1}\left(950^{\circ} \mathrm{C}\right)$, corresponding to increase in compressive stress for the films. FWHM of the diamond peak, on the other hand, decreased from $7.4\left(750^{\circ} \mathrm{C}\right) \mathrm{nm}$ to $5.8 \mathrm{~nm}$ $\left(950^{\circ} \mathrm{C}\right)$.

\subsection{Photoluminescence Spectra}

The PL spectra for the set of the films grown at different $\mathrm{SiH}_{4}$ percentage added in gas are shown in Figure 8. The PL spectra for all samples exhibit a strong SiV peak at $738 \mathrm{~nm}$, with intensity much higher than that of Raman peak. No nitrogen-related PL peaks, $\mathrm{NV}^{0}(575 \mathrm{~nm})$ or $\mathrm{NV}^{-}(637 \mathrm{~nm})$, are observed, indicating negligible, if any, etching of AIN substrate by plasma. The nominally undoped film (no silane added) yet shows a weak SiV peak as a result of silicon contamination in the film due to unintentional plasma etching of Si-containing layers on the reactor chamber walls accumulated from previous doping experiments.

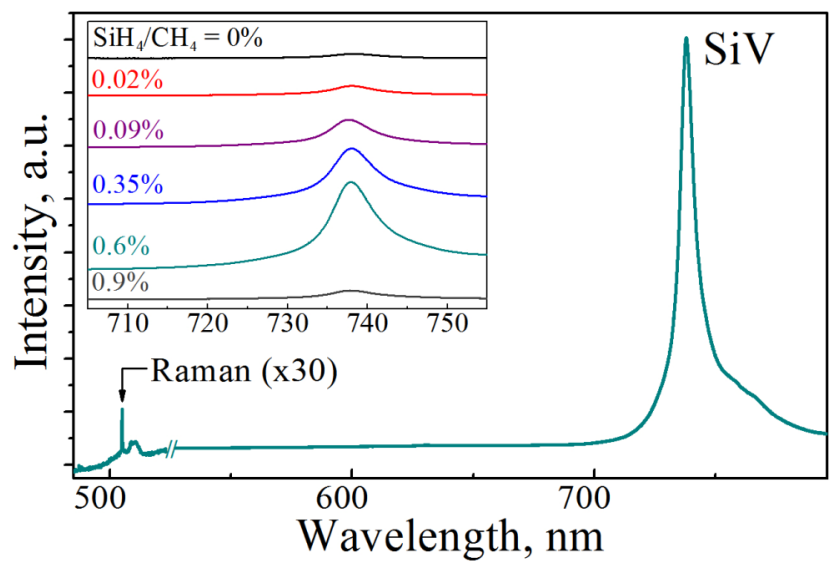

Figure 8: $\mathrm{PL}$ of diamond films grown at different $\mathrm{SiH}_{4} / \mathrm{CH}_{4}$ ratios, demonstrating the strong peak at $738 \mathrm{~nm}$ belonging to SiV defect. Note a decrease in $\mathrm{PL}$ for most doped sample $\left(\mathrm{SiH}_{4} / \mathrm{CH}_{4}=0.9 \%\right)$.
The most interesting observation is a nonmonotonic evolution of the SiV peak intensity with the $\mathrm{SiH}_{4} / \mathrm{CH}_{4}$ ratio in gas: first, the $\mathrm{PL}$ at $738 \mathrm{~nm}$ increases at low $0 \%-0.6 \% \mathrm{SiH}_{4} / \mathrm{CH}_{4}$ concentrations, then it drops at further $\mathrm{SiH}_{4}$ addition. The plot for integrated SiV PL signal (the area under peak), normalized to integrated diamond Raman peak intensity, against silane content in gas, is displayed in Figure 9. The SiV PL width (FWHM) $\Delta \mathrm{v}_{\mathrm{SiV}}$ of $7.3 \pm 0.5 \mathrm{~nm}$ showed no trend with $\mathrm{SiH}_{4}$ addition. Also, the SiV PL line position for all samples was in the narrow range of $738.3 \pm 0.3 \mathrm{~nm}$, being shifted by $0.2 \mathrm{~nm}$ to shorter wavelengths in comparison with the ZPL position of $738.5 \pm 0.3 \mathrm{~nm}$ in low-strained homoepitaxial diamond films [19]. This $0.2 \mathrm{~nm}$ shift can be ascribed to the compressive stress in our films as deduced from Raman analysis. We were not able to find in literature the data on the SiV PL shift with the biaxial applied stress. Sternschulte et al. [20] measured the SiV ZPL position under uniaxial stress a for homoepitaxial diamond film along the $<001>$ crystal direction at low (10K) temperature. They observed a splitting of ZPL for a doublet, and the linear shift of the main component of the doublet $(1682 \mathrm{meV})$ with the

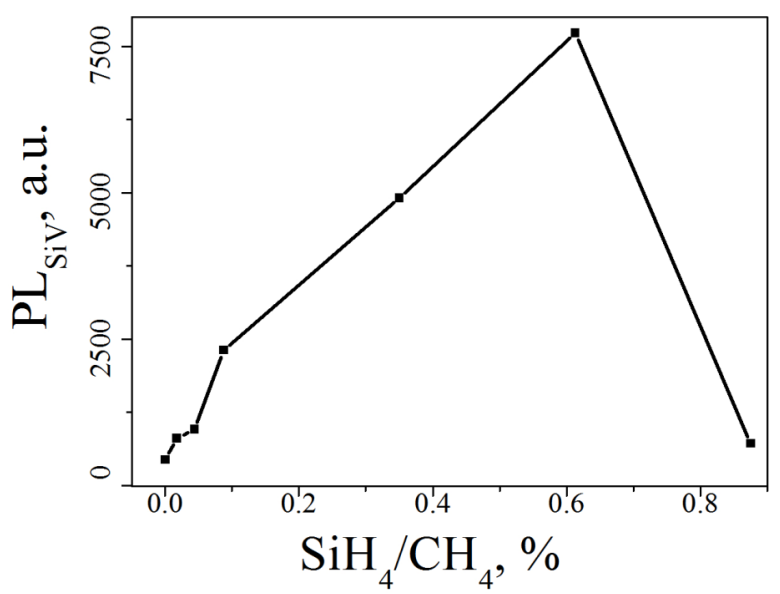

Figure 9: Dependence of integrated SiV PL intensity on $\mathrm{SiH}_{4} / \mathrm{CH}_{4}$ ratio used to deposit diamond films at $800^{\circ} \mathrm{C}$. The integrated SiV intensity is normalized to integrated diamond Raman peak intensity at $1336 \mathrm{~cm}^{-1}$. The solid line is the guide for eyes. 
stress with the rate of $-2 \mathrm{meV} / \mathrm{GPa}$ (or $+0.8 \mathrm{~nm} / \mathrm{GPa}$ ), while the second component revealed a shift to positive energies. The integrated shift of ZPL is by order of magnitude lower $(\sim 0.2 \mathrm{~nm} / \mathrm{GPa})$, as a result of this compensation. In our case $\mathrm{f}$ the expected ZPL shift is $\sim 0.35 \mathrm{~nm}$ or the measured stress of $1.8 \mathrm{GPa}$, that is in a reasonable agreement with the observed ZPL position.

The existence of an optimum silane concentration in gas to maximize the SiV PL intensity has been observed by other authors [11-13]. The PL quenching in isolated microscale diamond particles grown by microwave plasma CVD was explained [12] by increase of amorphous carbon (a-C) impurity abundance in diamond at high silane contents $(>0.08 \%)$, as confirmed by Raman spectra. The SiV PL decrease in MCD films deposited on Si substrates by a hot filament CVD at silane concentrations above $0.4 \%$ has been attributed [11] to the effect of concentration quenching of the luminescence via nonradiative energy dissipation. In contrast, we did not reveal, on the basis of the Raman spectra, a significant degradation of the film structure in terms of $\mathrm{sp}^{2} / \mathrm{sp}^{3}$ ratio or diamond Raman peak width (Figure 5) even at highest $\mathrm{SiH}_{4} / \mathrm{CH}_{4}$ concentrations. Therefore we don't ascribe the $\mathrm{PL}$ quenching to Si-induced a-C formation in the films, while some defects caused by $\mathrm{Si}$ incorporation in diamond may play a role, those defects, however, not manifesting itself in the diamond Raman peak broadening. The measurements of total $\mathrm{Si}$ concentration by secondary ion mass spectrometry (SIMS) in the $0.6 \% \mathrm{SiH}_{4} / \mathrm{CH}_{4}$ sample (with the brightest $\mathrm{PL}$ ) and the $0.9 \% \quad \mathrm{SiH}_{4} / \mathrm{CH}_{4}$ sample (with quenched $\mathrm{PL}$ ), determined high values of ca. $4000 \mathrm{ppm}$ and $9000 \mathrm{ppm}$ for these films, respectively [21]. Recently [19] we observed a similar effect of PL SiV quenching in epitaxial diamond films also doped from silane, and we found a significant broadening of PL SiV line width at low temperatures $(T=5 \mathrm{~K})$ for the single crystal samples with quenching $\mathrm{PL}$, while no change in diamond Raman peak and the $738 \mathrm{~nm}$ ZPL width has been seen at R.T. It was concluded [19] that the ZPL width is much more sensitive to defects in the direct vicinity of the SiV centers than the Raman line is. Qualitatively we explained this difference in sensitivity in the following way. The large $\mathrm{Si}$ atom disturbs the diamond lattice around its position inducing a local strain field. The formation of SiV center could also be accompanied by appearance of strain and point defects is its vicinity. The total volume of the strained (defective) domains is relatively small, and it contributes a little to Raman spectrum, but the SiV ZPL is more sensitive, it can be broaden at low temperatures due to proximity of the SiV center to those defects. The ZPL broadening was possible to see owing to initially small width $\left(\Delta \lambda_{737}=0.3 \mathrm{~nm}\right)$ of $\mathrm{ZPL}$ at $\mathrm{T}=5 \mathrm{~K}$ for low-doped (less than $0.6 \% \mathrm{SiH}_{4} / \mathrm{CH}_{4}$ ) homoepitaxial samples, while no increase in ZPL width at room temperature with Si doping was observed because of the ZPL large width $(\sim 7 \mathrm{~nm})$ at R.T. Similar consideration can be applied for polycrystalline diamond films as well. The local stress could be caused by a variety of defects such as interstitial atoms, Si impurity atoms or their aggregations, and other structural point or extended defects. What particular defect triggers the PL quenching remains, however, unclear at present time.

The mapping of the PL SiV emission over $30 \times 30 \mu \mathrm{m}$ was performed for one the doped film, and compared with the AFM image of the relief, taken by the same instrument (Figure 10). The chosen field of view included a large number $(\sim 100)$ of the grains to get enough statistics for $738 \mathrm{~nm}$ line intensity distribution. The PL map shows a grainy pattern (Figure 10b), the brightest area not necessarily coincide with relief's protrusions. The spotty PL distribution might be a result of anisotropy in Si incorporation probability in different facets of the crystallites (the phenomenon well known, for example, for nitrogen incorporation in HPHT diamond) [22]. Another reason can be connected to angle diagram of the SiV emission. The SiV defects are aligned along <111> directions [23], the SiV dipoles emit perpendicularly to $\langle 111\rangle$, therefore the (111) planes, when oriented perpendicularly to
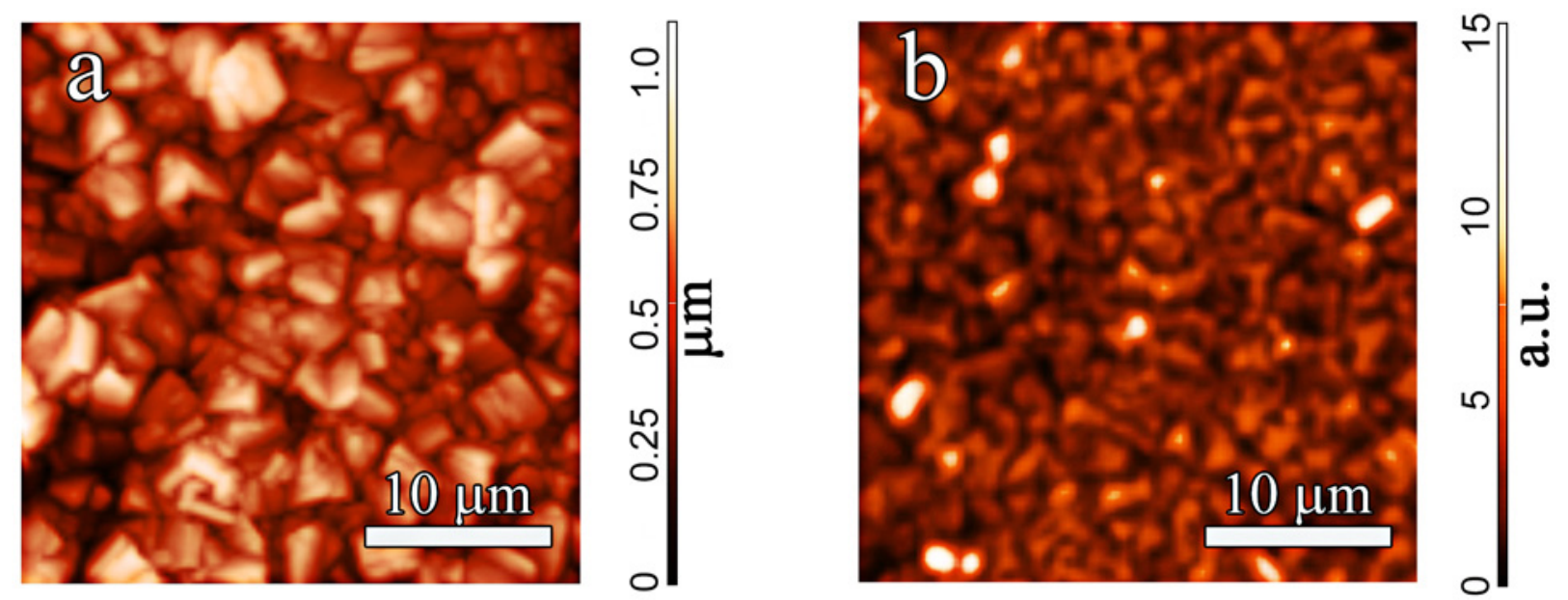

Figure 10: AFM image of a Si-doped microcrystalline diamond film grown at $\mathrm{SiH}_{4} / \mathrm{CH}_{4}=0.6 \%$ (a), and $738 \mathrm{~nm} \mathrm{PL}$ map for the same region (b). The PL excitation was at $632 \mathrm{~nm}$. 

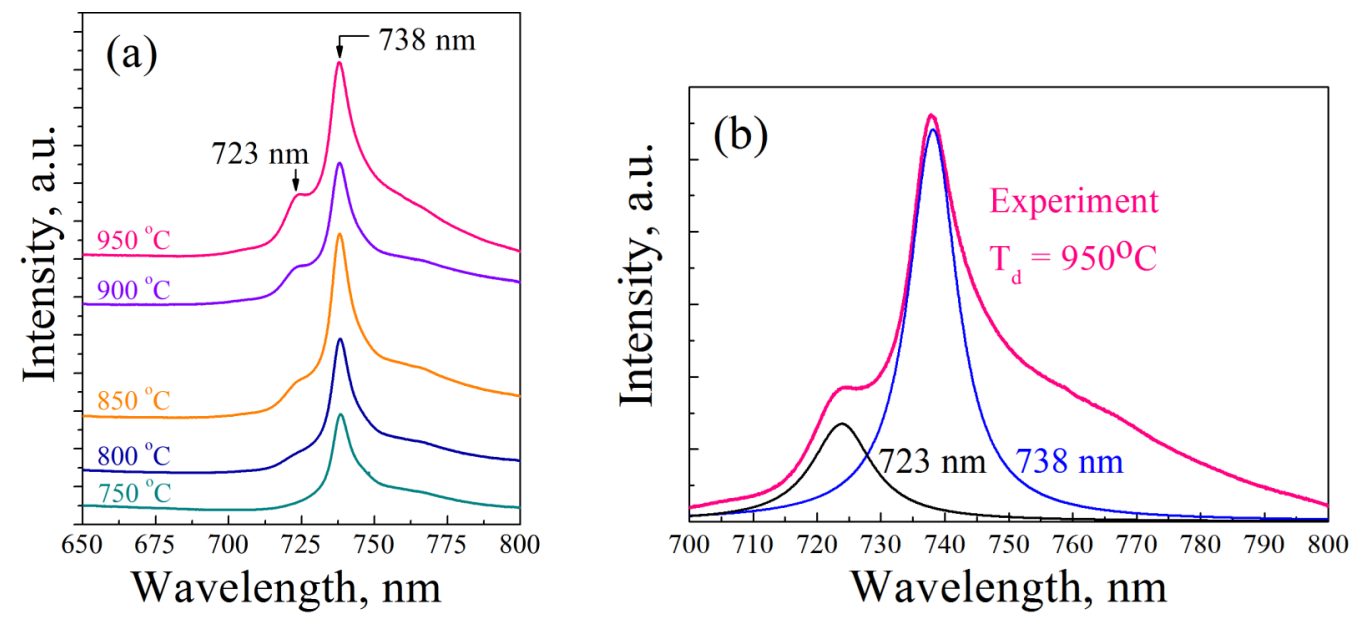

Figure 11: $\mathrm{PL}$ spectra for the films grown at different substrate temperatures at $\mathrm{SiH}_{4} / \mathrm{CH}_{4}=0.6 \%(\mathbf{a})$ and approximation of experimental line with two Lorentzians (b). Note the appearance of a side band at $723 \mathrm{~nm}$ for $\mathrm{T}_{d}>800^{\circ} \mathrm{C}$.

the excitation beam, make largest contribution to emission collected with the objective of optical microscope viewing normally to the sample surface. In addition, the grains of better quality could promote the stronger PL yield.

The SiV PL intensity demonstrates a monotonic increase with the substrate temperature beginning with $\approx 750^{\circ} \mathrm{C}$ (Figures 11 and 12), the $Z P L$ at $738 \mathrm{~nm}$ rising approximately twice at $\mathrm{T}_{\mathrm{d}}=950^{\circ} \mathrm{C}$. This indicates that the choice of the optimal substrate temperature can maximize the $738 \mathrm{~nm}$ line emission. In addition, a side band at $723 \mathrm{~nm}$ appears and enhances together with SiV peak intensity at $T_{d}>800^{\circ} \mathrm{C}$ (Figures 11 and 12). This band is not the vibronic one as it lies in anti-Stokes range. Turukhin et al. [24] observed the $723 \mathrm{~nm}$ peak for free-standing polycrystalline diamond films grown on $\mathrm{Si}$ substrate and ascribed it to $\mathrm{sp}^{2}$ nondiamond carbon phase. Similar peak has been reported by Davydov et al. [25] for Si-doped micro-and nanocrystalline diamond particles synthesized by HPHT technique who also treated it as a PL signal from a graphite-like contamination. In our case, however, the intensity of the $723 \mathrm{~nm}$ band is much

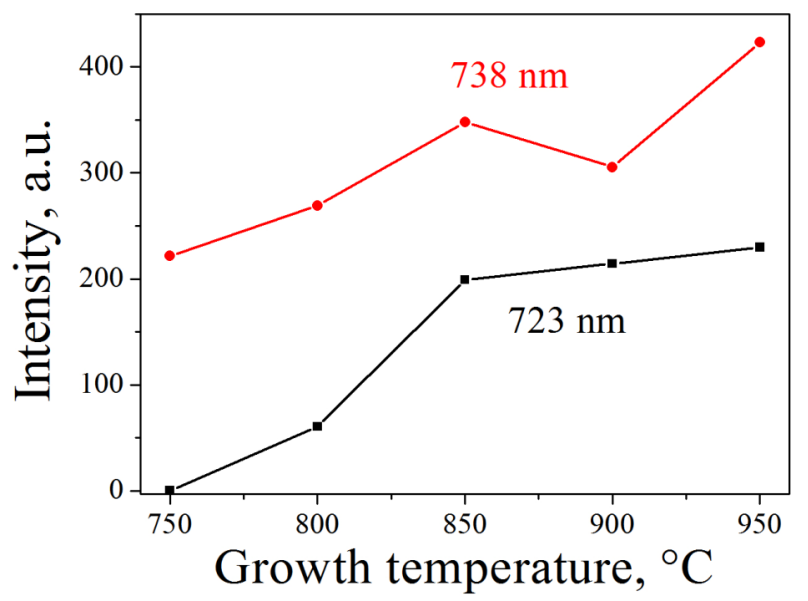

Figure 12: Dependence of integrated intensities for ZPL at $738 \mathrm{~nm}$ and the $723 \mathrm{~nm}$ side-band in PL spectra for the films grown at different substrate temperatures at $\mathrm{SiH}_{4} / \mathrm{CH}_{4}=0.6 \%$. stronger relative to $Z P L$ at $738 \mathrm{~nm}$ (the integrated $723 \mathrm{~nm}$ band it amounts up to $50 \%$ of that for ZPL (Figure 12) than in those works, and the band width of $15-30 \mathrm{~nm}$ seems to be too small compared to typical PL bands related to a-C phase $[26,27]$. Moreover, the contribution of non-diamond carbon in the Raman spectra reduces with $T_{d}$ as seen in Figure 7. This brings into a question the assignment of $723 \mathrm{~nm}$ band to a graphitic carbon, so the origin of the $723 \mathrm{~nm}$ band, to our opinion, is needed in a further study.

\section{CONCLUSIONS}

We produced microcrystalline diamond films on AIN substrates with bright $\mathrm{PL}$ of SiV color centers at $738 \mathrm{~nm}$ wavelength using a microwave plasma CVD technique. The $\mathrm{PL}$ intensity is controlled by doping the films with $\mathrm{Si}$ via adding silane to $\mathrm{CH}_{4}-\mathrm{H}_{2}$ gas mixtures in the course of the deposition process. Within the $\mathrm{SiH}_{4} / \mathrm{CH}_{4}$ ratios explored $(0-$ $0.9 \%$ ) the dependence of SiV PL intensity of the films on the silane concentration in gas shows a maximum at certain $\mathrm{SiH}_{4} / \mathrm{CH}_{4}$ ratio followed by the $\mathrm{PL}$ quenching at high doping levels. No relation of this quenching effect with amorphous carbon formation is established. The applied in situ doping from gas phase is an easy and effective way to incorporate $\mathrm{Si}$ in diamond. The Si-doped microcrystalline films can be a convenient starting material for preparation of luminescent CVD diamond nanoparticles [8]. In addition, by doping from silane, localized PL SIV emitters can be grown using selective area seeding [28] or direct growth of diamond film through windows in a mask on diamond substrate [29], as it was demonstrated previously with solid Si dopant sources.

\section{ACKNOWLEDGEMENTS}

The authors would like to thank Prof. A.Ya. Vul for kind provision of nanodiamond slurry.

This study was supported by the Russian Foundation for Basic Research (grants No. 14-02-31772_mol_a, 14-02- 
31739_mol_a and 15-52-04073_Bel_mol), Belarusian Republican Foundation for Fundamental Research (grants No. F15RM-046) and the grant of the President of the Russian Federation (No. SP-2575.2015.5).

\section{REFERENCES}

[1] Balmer RS, Brandon JR, Clewes SL, et al. Chemical vapour deposition synthetic diamond: materials, technology and applications. J Phys: Condens Matter 2009; 21: 364221 http://dx.doi.org/10.1088/0953-8984/21/36/364221

[2] Uhlmann E, Sammler F. CVD coated diamond tools for the machining of lightweight materials. Adv Mater Res 2014; 907: 63-73. http://dx.doi.org/10.4028/www.scientific.net/AMR.907.63

[3] Silva FJG, Fernandes AJS, Costa FM, Teixeira V, Baptista APM, Pereira E. Tribological behaviour of CVD diamond films on steel substrates. Wear 2003; 255: 846-53.

http://dx.doi.org/10.1016/S0043-1648(03)00145-5

[4] Yang N, Ed. Novel Aspects of Diamond: From Growth to Applications. Berlin: Springer; 2015.

[5] Szunerits S, Nebel CE, Hamers RJ. Surface functionalization and biological applications of CVD diamond. MRS Bulletin 2014; 39: 51724.

http://dx.doi.org/10.1557/mrs.2014.99

[6] Aharonovich I, Neu E. Diamond nanophotonics. Adv Opt Mater 2014; 2: 911-28.

http://dx.doi.org/10.1002/adom.201400189

[7] Prawer S, Aharonovich I. Quantum information processing with diamond: principles and applications. Elsevier; 2014. 367 p.

[8] Neu E, Arend C, Gross E, et al. Narrowband fluorescent nanodiamonds produced from chemical vapor deposition films. Appl Phys Lett 2011; 98: 243107. http://dx.doi.org/10.1063/1.3599608

[9] Hui YY, Cheng C-L, Chang H-C. Nanodiamonds for optical bioimaging. J Phys D: Appl Phys 2010; 43: 374021. http://dx.doi.org/10.1088/0022-3727/43/37/374021

[10] Wang L, Lei X, Shen B, Sun F, Zhang Z. Tribological properties and cutting performance of boron and silicon doped diamond films on Cocemented tungsten carbide inserts. Diam Relat Mater 2013; 33: 5462.

\section{http://dx.doi.org/10.1016/i.diamond.2013.01.004}

[11] Musale DV, Sainkar SR, Kshirsagar ST. Raman, photoluminescence and morphological studies of $\mathrm{Si}$ - and $\mathrm{N}$-doped diamond films grown on $\mathrm{Si}(100)$ substrate by hot-filament chemical vapor deposition technique. Diam Relat Mater 2002; 11: 75-86.

http://dx.doi.org/10.1016/S0925-9635(01)00521-0

[12] Grudinkin SA, Feoktistov NA, Medvedev AV, et al. Luminescent isolated diamond particles with controllably embedded silicon-vacancy color centres. J Phys D: Appl Phys 2012; 45: 062001. http://dx.doi.org/10.1088/0022-3727/45/6/062001

[13] Cui Y, Zhang J, Sun F, Zhang Z. Si-doped diamond films prepared by chemical vapour deposition. Trans Nonferrous Met Soc China 2013; 23: 2962-70.

http://dx.doi.org/10.1016/S1003-6326(13)62821-6

[14] Sedov VS, Ralchenko VG, Vlasov II, et al. Photoluminescence of Sivacancy color centers in diamond films grown in microwave plasma in methane-hydrogen-silane mixtures. Bull Lebedev Phys Inst 2015; 41: 359-63.

http://dx.doi.org/10.3103/S1068335614120057
[15] Smolin AA, Ralchenko VG, Pimenov SM, Kononenko TV, Loubnin EN. Optical monitoring of nucleation and growth of diamond films. Appl Phys Lett 1993; 62: 3449-51.

http://dx.doi.org/10.1063/1.109045

[16] Vlasov II, Goovaerts E, Ralchenko VG, Konov VI, Khomich AV Kanzyuba MV. Vibrational properties of nitrogen-doped ultrananocrystalline diamond films grown by microwave plasma CVD. Diam Relat Mater 2007; 16: 2074-7. http://dx.doi.org/10.1016/i.diamond.2007.07.007

[17] Yim WM, Paff RJ. Thermal expansion of AIN, sapphire, and silicon. J Appl Phys 1974; 45: 1456-7.

http://dx.doi.org/10.1063/1.1663432

[18] Ager JW. Residual Stress in Diamond and Amorphous Carbon Films. Symposium I - Mechanical Behavior of Diamond and Other Forms of Carbon. 1995.

[19] Bolshakov A, Ralchenko V, Sedov V, et al. Photoluminescence of SiV centers in single crystal CVD diamond in situ doped with Si from silane. Phys Status Solidi A (2015);

[20] Sternschulte H, Thonke K, Sauer R, Münzinger PC, Michler P. 1.681eV luminescence center in chemical-vapor-deposited homoepitaxial diamond films. Phys Rev B 1994; 50(19): 14554-60. http://dx.doi.org/10.1103/PhysRevB.50.14554

[21] Sedov V, Ralchenko V, Khomich AA, et al. Si-dopednano- and microcrystalline diamond films with controlled brigh photoluminescence of silicon-vacancy color centers. Diam Relat Mater. 2015; 56: 23-8.

http://dx.doi.org/10.1016/j.diamond.2015.04.003

[22] Burns RC, Cvetkovic V, Dodge CN, et al. Growth-sector dependence of optical features in large synthetic diamonds. J Cryst Growth. 1990 104(2): 257-79.

http://dx.doi.org/10.1016/0022-0248(90)90126-6

[23] Rogers LJ, Jahnke KD, Doherty MW, et al. Electronic structure of the negatively charged silicon-vacancy center in diamond. Phys Rev B. 2014; 89(23): 235101.

http://dx.doi.org/10.1103/PhysRevB.89.235101

[24] Turukhin AV, Liu C-H, Gorokhovsky AA, Alfano RR, Phillips W. Picosecond photoluminescence decay of Si-doped chemical-vapordeposited diamond films. Phys Rev B. 1996; 54(23): 16448-51. http://dx.doi.org/10.1103/PhysRevB.54.16448

[25] Davydov VA, Rakhmanina AV, Lyapin SG, et al. Production of nanoand microdiamonds with $\mathrm{Si}-\mathrm{V}$ and $\mathrm{N}-\mathrm{V}$ luminescent centers at high pressures in systems based on mixtures of hydrocarbon and fluorocarbon compounds. Jetp Lett. 2014; 99(10): 585-9. http://dx.doi.org/10.1134/S002136401410004X

[26] Fabisiak K, Bała W, Paprocki K, Szreiber M, Uniszkiewicz C. Broad band photoluminescence studies of diamond layers grown by hotfilament CVD. Opt Mater. 2009; 31(12): 1873-6. http://dx.doi.org/10.1016/i.optmat.2009.02.020

[27] Smith BR, Gruber D, Plakhotnik T. The effects of surface oxidation on luminescence of nano diamonds. Diam Relat Mater. 2010; 19(4): 314 8

http://dx.doi.org/10.1016/j.diamond.2009.12.009

[28] Singh S, Thomas V, Martyshkin D, Kozlovskaya V, Kharlampieva E Catledge SA. Spatially controlled fabrication of a bright fluorescent nanodiamond-array with enhanced far-red Si-V luminescence. Nanotechnology 2014; 25(4): 045302

http://dx.doi.org/10.1088/0957-4484/25/4/045302

[29] Sovyk D, Ralchenko V, Komlenok M, et al. Fabrication of diamond microstubphotoemitters with strong photoluminescence of SiV colo centers: bottom-up approach. Appl Phys A. 2014; 118(1): 17-21. http://dx.doi.org/10.1007/s00339-014-8877-2

(c) 2015 Sedov et al.; Licensee Lifescience Global.

This is an open access article licensed under the terms of the Creative Commons Attribution Non-Commercial License (http://creativecommons.org/licenses/by-nc/3.0/) which permits unrestricted, non-commercial use, distribution and reproduction in any medium, provided the work is properly cited. 